\title{
Production and characterization of monoclonal antibodies to oxidized LDL
}

\author{
Kyungho Choi, ${ }^{1}$ Hyun Soon Lee ${ }^{2}$ and \\ Hong Keun Chung ${ }^{1,3}$ \\ 1 Department of Biochemistry, Seoul National \\ University College of Medicine, Seoul, Korea \\ 2 Department of Pathology, Seoul National University \\ College of Medicine, Seoul, Korea \\ 3 Corresponding author \\ Accepted 16 March 1998
}

Abbreviations: MDA-LDL, malondialdehyde-conjugated low density lipoprotein; oxLDL, oxidized LDL; BSA, bovine serum albumin; ECL, enhanced chemiluminescence; ELISA, Enzyme-linked immunosorbent assay; TBARS, thiobarbituric acid-reacting substance; MDA-BSA, malondialdehyde-modified BSA pathogenesis of atherosclerosis than LDL itself does (Haberland et al., 1988). Modified LDL deteriorates macrophage to foam cell via scavenger receptors, which is considered to be important in the initial atheroma formation, but LDL does not (Brown et al., 1983; Goldstein et al., 1979). Especially, oxidative modifications of LDL are sure to be invloved in the atherogenesis through many actions such as chemotaxis of monocytes (Ylä-Herttuala et al., 1991), induction of adhesion molecules on the endothelial cells (Carlos et al., 1990; Lehr et al., 1992) and vascular constriction (Chin et al., 1992). Oxidized LDL (oxLDL) also seems to be a golden mediator of lipid-driven renal injury (Keane et al., 1990; Lee et al., 1991; Magil et al., 1993). Convincing evidence for the oxidative modification in lesion formation comes from studies demonstrating that antioxidants such as probucol (Carew et al., 1987; Kita et al., 1987) or butylated hydroxytoluene (Bjorkham et al., 1991) can inhibit lesion formation in WHHL (Watanabe Heritable Hyperlipidemic) rabbit and cholesterol-fed rabbits.

The presence of oxLDL in vivo has been reported in the arterial or glomerular lesions of experimental animals (Harberland et al., 1988; Palinsky et al., 1989; Magil et al., 1993), and LDL extracted from arterial lesions resembles in vitro oxLDL in the physical properties and immunoreactivity with antibodies directed against epitopes of oxLDL (Palinsky et al., 1989). But it is not shown yet that oxLDL exists and fuctions in human patient's lesion or serum. Therefore, we decided to develop monoclonal antibodies recognizing oxLDL to verify the existence of oxLDL in human tissues and to clarify its roles in them.

\section{Materials and Methods}

\section{Materials}

Bovine serum albumin (BSA), hypoxanthine, aminopterin, thymidine, polyethylene glycol 1500, and 1,1,3,3-tetramethoxypropane were purchased from Sigma Chemical Co. Media and fetal bovine serum were obtained from Gibco/BRL Co. Goat anti-mouse IgG, A, M was from $\mathrm{Kpl}$ Co. Nitrocellulose membrane and enhanced chemilumine-scence (ECL) detection reagent was from Amersham Co.

\section{Purification and oxidation of LDL}

Native human LDL was isolated from normal human plasma by ultracentrifugation as described in the previous papers (Lee et al., 1994; Goldstein et al., 1983). oxLDL was prepared by incubating LDL with $5 \mu \mathrm{M} \mathrm{Cu}^{2+}$ at $37^{\circ} \mathrm{C}$ for $24 \mathrm{~h}$. Oxidation was stopped by the addition of 200 
$\mu \mathrm{M}$ EDTA and $40 \mu \mathrm{M}$ butylated hydroxytoluene.

\section{Production of Monoclonal antibodies}

After immunizing Balb/c mice with $100 \mu \mathrm{g}$ of oxLDL 4 times at 1-month intervals, splenocytes were isolated and fused with SP2 mouse myeloma cells in the presence of $50 \%$ polyethylene glycol according to the method of Köler and Milstein described in our previous paper (Chung et al., 1984). Hybridomas were selected with HAT selection medium in a 96 well plate, and about 10 days later, the culture supernatants were screened for the presence of antibody to oxLDL by double ELISAs in which 96-well plates were coated with native LDL and oxLDL respectively. Cloning by limiting dilution and repeated screening were performed to select stable cell lines (Suh et al., 1985). The isotype of monoclonal antibodies was determined using mouse monoclonal isotyping kit (Hyclone EK-5050) according to the manufacturer's instruction.

\section{Production of ascitic fluids}

Cultured hybridoma cells $\left(5 \times 10^{6}-1 \times 10^{7}\right)$ were inoculated into the peritoneal cavity of Balb/c mice pretreated with $0.5 \mathrm{ml}$ of incomplete Freund's adjuvant 3 days before (Mueller et al., 1986). After 10 to 14 days, ascitic fluids were collected.

\section{Delipidation of oxLDL}

Fifty volume of ice-cold ethanol-ether $(3: 2 \mathrm{v} / \mathrm{v})$ was added to a solution of $500 \mu \mathrm{g}$ of oxLDL and after $2 \mathrm{~h}$ incubation at $-20^{\circ} \mathrm{C}$, the mixture was centrifuged at $5000 \mathrm{rpm}$ for 10 $\mathrm{min}$. The pellets were washed twice with ethanol-ether $(3: 2 \mathrm{v} / \mathrm{v})$. Air-dried pellets were dissolved in $1 \times$ Lammeli buffer and stored at $-20^{\circ} \mathrm{C}$.

\section{Modification of LDL and BSA}

To make $0.2 \mathrm{M}$ malondialdehyde stock solution, $164 \mu \mathrm{l}$ of tetramethoxypropane and $200 \mu \mathrm{l}$ of $12 \mathrm{~N} \mathrm{HCl}$ were mixed and incubated for $1.5 \mathrm{~min}$. After the addition of $4.6 \mathrm{ml}$ of $0.1 \mathrm{M}$ sodium phosphate, the solution was adjusted to $\mathrm{pH} 6.0$ with $\mathrm{NaOH}$.

LDL or BSA $(10 \mathrm{mg} / \mathrm{ml})$ was incubated with an equal volume of malondialdehyde stock solution for $3 \mathrm{~h}$ at $37^{\circ} \mathrm{C}$, and then dialyzed overnight against PBS (phosphate buffered saline) to remove free malondialdehyde (Fogelman

Table 1. Isotypes and antigen specificity of monoclonal antibodies.

\begin{tabular}{llcc}
\hline $\begin{array}{l}\text { monoclonal } \\
\text { antibodies }\end{array}$ & isotype & \multicolumn{2}{c}{ antigen binding } \\
& & native LDL & oxLDL \\
\hline OL10 & IgM & - & + \\
OL13 & IgM & - & + \\
OL1 & IgM & + & + \\
OL6 & IgM & + & + \\
OL11 & IgM & + & + \\
\hline
\end{tabular}

et al., 1980)

Immunoblot

Protein samples were electrophoresed under the denaturing condition, and transferred to a nitrocellulose membrane. The membrane was blocked with $5 \%$ nonfat dry milk in TBS (tris-buffered saline) for an hour and then incubated with anti-oxLDL antibodies for an hour. Peroxidaselabelled anti-mouse $\mathrm{Ig}$ was used as a secondary probe and visualization was performed with ECL.

\section{Enzyme-linked immunosorbent assay (ELISA)}

ELISA was performed using various proteins as antigens. Microtiter plates were coated with each antigen at $4^{\circ} \mathrm{C}$ overnight. After blocking with $3 \%$ BSA in PBS, the plates were incubated with serially diluted ascitic fluids. followed by treatment of peroxidase-labelled anti-mouse Ig. The aborbance was measured at 490nm after the enzyme reaction using 0 -phenylenediamine and $\mathrm{H}_{2} \mathrm{O}_{2}$ as substrates.

\section{Thiobarbituric acid-reacting substance (TBARS) assay}

$0.5 \mathrm{ml}$ of trichloroacetic acid and $0.5 \mathrm{ml}$ of thiobarbituric acid were added sequentially to $50 \mu$ of protein solution and boiled for $45 \mathrm{~min}$. After cooling in ice, the reaction mixture was centrifuged at 15,000 r.p.m. for 2 min and the absorbance of the supernatant was measured at $532 \mathrm{~nm}$. The parallel reaction using malondialdehyde bis was performed to get the standard curve of TBARS.

\section{Results}

\section{Selection of anti-oxLDL monoclonal antibody}

As a result of cell fusion and cloning, 4 clones could be obtained, which secreted monoclonal antibodies recognizing oxLDL, but not native LDL. Two of them showed high background signals on immunoblotting, thus the rest two, OL10 and OL13, were chosen. In addition, several monoclonal antibodies reacted with both oxLDL and native LDL. Table 1 shows representative monoclonal antibodies and their reactivity with antigens.

\section{Characterization of OL10 and OL13-recognizing epitopes}

When native LDL and oxLDL were elctrophoresed, transferred to a nitrocellulose membrane and probed with OL10 and OL13, both antibodies recognized high molecular weight (approx. $550 \mathrm{kDa}$ ) oxLDL, but did not bind to native LDL as shown in Figure 1. To identify the epitope of the antigen, oxLDL was delipidated and immunoblotted. OL10 and $\mathrm{OL} 13$ reacted with delipidated oxLDL, which suggest that epitopes recognized by these anti-bodies reside on the modified region of apoB100 rather than lipid 


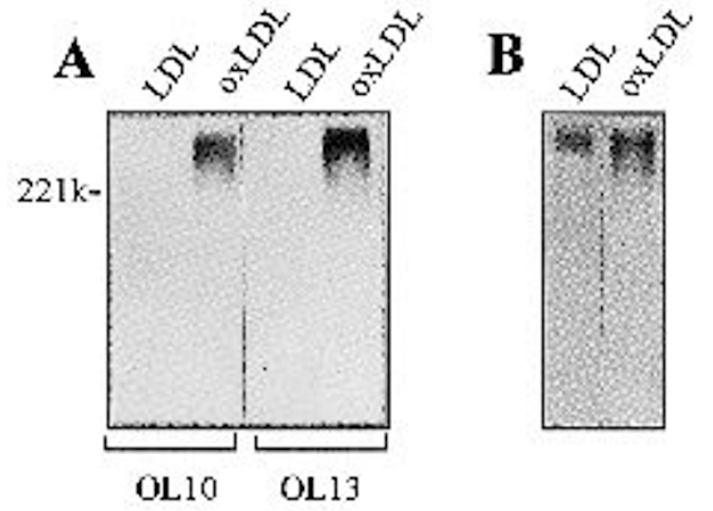

Figure 1. Specificity of the monoclonal antibodies for oxLDL.Thirty $\mu g$ of $L D L$ and oxLDL each was subjected to $8 \%$ SDS-PAGE under reducing conditions and transferred to a nitrocellulose membrane. The membrane was allowed to react with OL10 or OL13, followed by peroxidase-conjugated goat anti-mouse immunoglobulin and then was visualized by ECL $\mathbf{A}$. The gel was stained with Coomassie Blue $\mathbf{B}$.

compartment (Figure 2).

The conjugation of malondialdehyde to apoB100 is the most specifically-defined oxidative modification of LDL that has been described (Steinbrecher, 1987). To determine whether these antibodies recognize malondialdehydeconjugated peptide or not, LDL was treated with malondialdehyde, and SDS-PAGE and immunoblotting were performed. OL10 and OL13 reacted with malondialdehydeconjugated LDL (MDA-LDL)(Figure 3). The next question was whether the epitope recognized by antibodies was specific for LDL. Thus, we treated an irrelevant protein, BSA with malondialdehyde and tested it for binding to OL10 and OL13. The antibodies reacted with to malondialdehyde-conjugated BSA (MDA-BSA), indicating that they recognize malondialdehyde-conjugated peptide epitope irrespective of carrier protein (Figure 4).

\section{Immunoreactivity analysis of each antigen}

For the comparison of the immunoreactivity of various antigens with the antibodies, ELISA was performed using OL10 and OL13 as a primary probe (Figure 5). Native LDL and BSA did not show any reactivity with OL10 and OL13 respectively, but oxLDL, malondialdehyde-modified LDL, and malondialdehyde-modified BSA showed the strong reactivity.

The reactivity patterns correlated with the amount of malondialdehyde conjugated to each antigen, as measured by TBARS assay except native LDL (Figure 6). The

Figure 4. Reactivity of monoclonal antibodies with MDA-BSA. BSA was incubated with $0.2 \mathrm{M}$ malondialdehyde for $3 \mathrm{~h}$ at $37^{\circ} \mathrm{C}$ and dialyzed overnight. The MDA-BSA was electrophoresed on $8 \%$ SDS-PAGE which was analyzed by immunoblot with OL10 and OL13 A or stained with Coomassie Blue B.

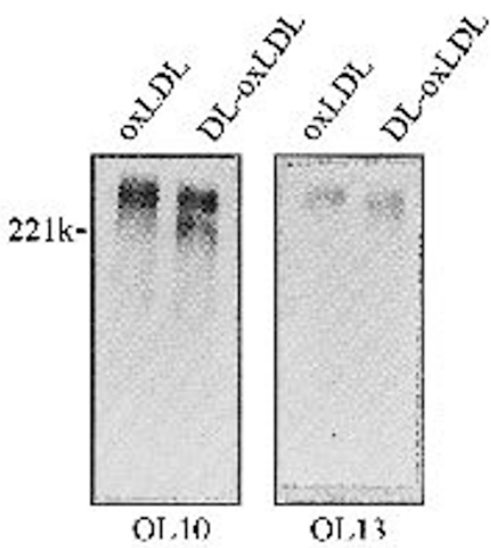

Figure 2. Reactivity of the monoclonal antibodies with delipidated oxLDL. oxLDL was delipidated by incubating with ethanol-ether ( $3: 2 \mathrm{v} / \mathrm{v})$ for $2 \mathrm{~h}$. After washing twice with ethanol-ether, delipidated oxLDL ( $D L-0 x L D L)$ was subjected to the same procedure as described in Figure 1 (A).

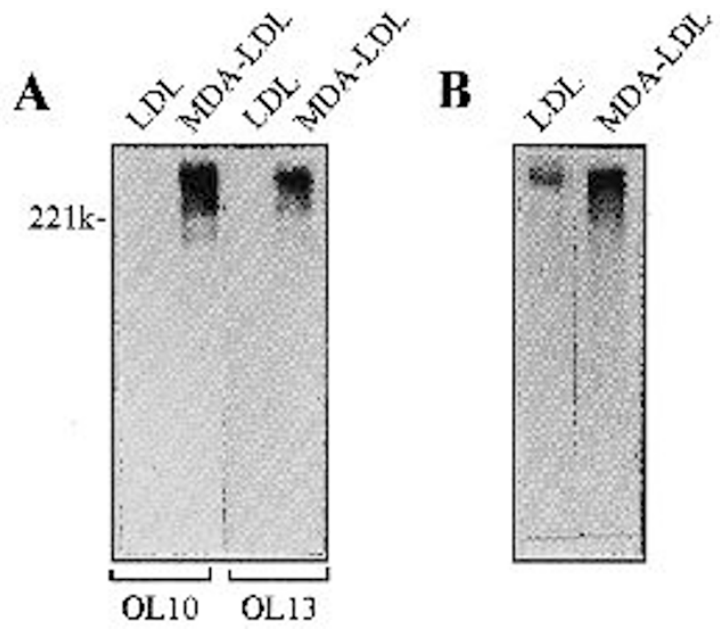

Figure 3. Reactivity of the monoclonal antibodies with malondialdehyde-modified LDL. $\mathrm{LDL}$ was incubated with $0.2 \mathrm{M}$ malondialdehyde for $3 \mathrm{~h}$ at $37^{\circ} \mathrm{C}$ and dialyzed overnight. The MDA-LDL was electrophoresed on $8 \%$ SDS-polyacrylamide gel which was analyzed by immunoblot with $\mathrm{OL} 10$ and $\mathrm{OL} 13 \mathrm{~A}$ or stained with Coomassie Blue B.
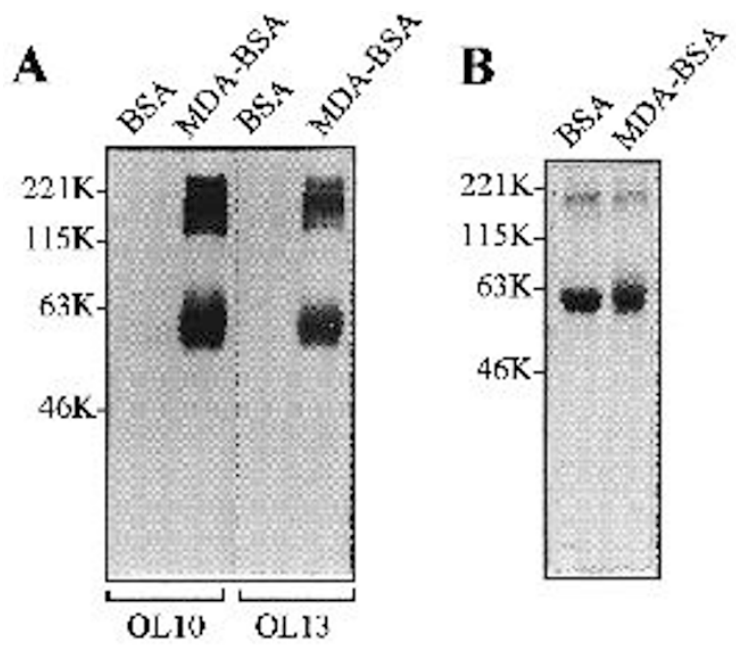
$\mathbf{A}$

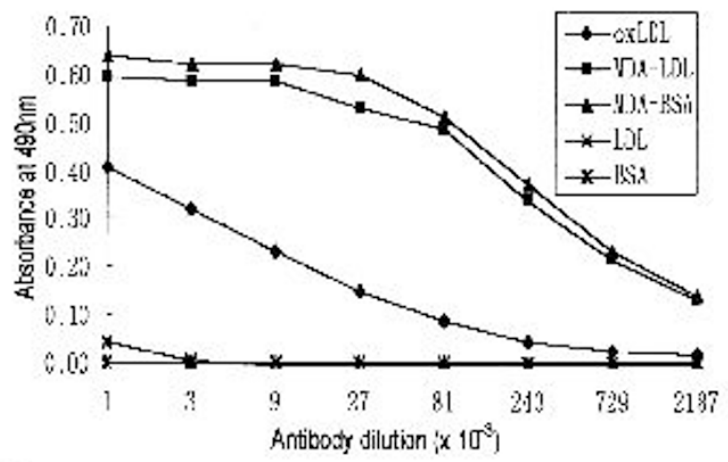

B

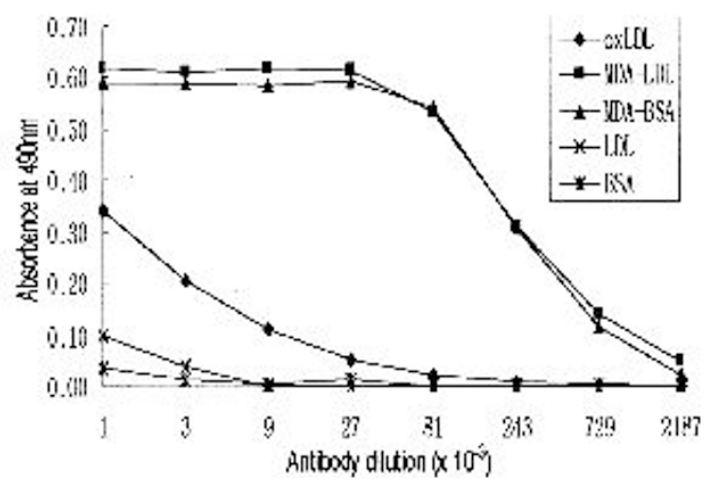

Figure 5. Immunoaffinity of the monoclonal antibodies. The microtiter plate was coated with each antigen at $4^{\circ} \mathrm{C}$ overnight. After blocking with $3 \% \mathrm{BSA}$ in PBS, the plate was incubated with serially diluted ascitic fluid of OL10 (A) or OL13 (B), followed by peroxidase-conjugated goat anti-mouse lg. The enzyme substrate solution (0phenylendiamine) was added and the absorbance was measured at $490 \mathrm{~nm}$.

difference in the measured amount of malondialdehyde between oxLDL and LDL was not so great, because malondialdehyde could be released from polyunsaturated fatty acids associated with apoB100, which was caused by peroxidation during TBARS assay.

\section{Discussion}

Many gene techniques such as in situ hybridization and Northern blot analysis are available for the detection of RNA of a certain protein in various samples. These methods cannot be employed to detect the modified proteins caused by posttranslational modification or oxidation. But antibody-mediated methods such as immunohistochemistry and enzyme immunoassay are useful in this aspect. Generally polyclonal antibody is the first choice, because its production is very simple, but it cannot be used in differentiating antigens which have common epitopes. A monoclonal antibody to a specific epitope of an antigen can overcome this limitation. To

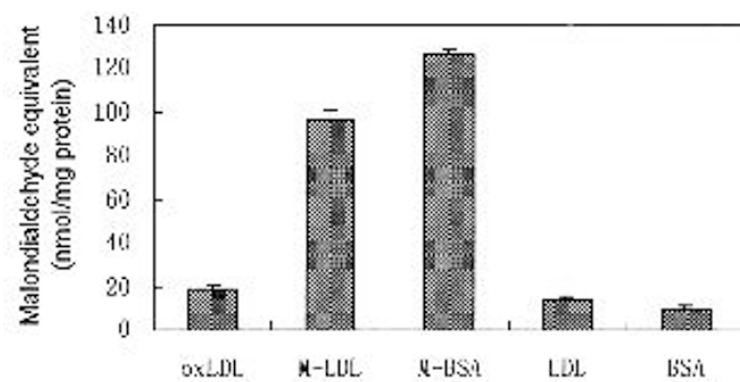

Figure 6. Malondialdehyde content in antigens. Each protein was boiled for $45 \mathrm{~min}$. in the presence of trichloroacetic acid and thiobarbituric acid. The absorbance was measured at $532 \mathrm{~nm}$ and malondialehyde equivalent was calculated from standard curve of malondialdehyde bis.

examine the role of oxLDL in diseases such as renal glomerular injury and atherosclerosis, it is essential to develop monoclonal antibodies to oxLDL. So we attempted to produce monoclonal antibodies to epitopes specific for oxLDL. We used oxLDL as immunogen and screened hybridomas by double ELISAs, in which the plates were coated with oxLDL and native LDL respectively. Finally we obtained monoclonal antibodies OL10 and OL13 recognizing oxLDL only.

It is well known that LDL is labile to oxidative modification, but it should be clear that oxLDL is not a single, homogeneous entity. There may be many forms of oxLDL which originated from peroxidation and fragmentation of lipid components of LDL and the modification and oxidative degradation of apoB. Nevertheless, it is well accepted now that derivatization of lysine residues of apoB protein is a major event in oxidative modification and the subsequent neutralization of positive charges of lysine residue causes oxLDL decreased in affinity for native LDL receptor (Brown et al. 1983). The nature of oxidative LDL is reported to be similar to that of malondialdehydemodified LDL (Steinbrecher, 1987). So we tried to find out which epitopes are the targets of our antibodies. Immunoblot analysis and binding affinity assay therefore were performed. The monoclonal antibody OL10 and OL13 bound to malondialdehyde-modified LDL as well as oxLDL, indicating that the antibodies recognized malondialdehyde-derivatized epitope. Moreover, the antibodies bound to malondialdehydemodified albumin so that they seem to recognize malondialdehyde-conjugated lysine residue rather than the lysine residue-containing peptide. This means the low specificity of OL10 and OL13, but they have so great ability to differentiate oxLDL from native LDL that they could be useful in immunohisto-chemistry and sandwich immunoassays if used in combi-nation with anti-LDL antibodies (Table 1). It is likely that the anti-oxLDL antibody renders all proteins with the malondialdehydeconjugated lysine residue well exposed stainable by immunohisochemistry. But, in fact, proteins other than 
LDL do not seem to be easily conjugated with malondialdehyde, because most proteins do not so closely contact with polyunsaturated fatty acids as LDL. In many cases of immunohistchemical staining, therefore, it is probable that stainings with the anti-oxLDL antibody represent oxLDL, but for the purpose of confirmation, double staining using anti-oxLDL and anti-LDL antibodies as primary antibodies is performed. In sandwich immunoassays in which both anti-oxLDL antibody and anti-LDL antibody are used, malondialdohyde-conjugated proteins other than oxLDL are eliminated, because of the specificity of anti-LDL antibody.

\section{Acknowledgement}

This strudy was supported by Basic Medical Research Fund, Ministry of Education (1995 - 1997).

\section{References}

Bjorkham, I., Henriksson-Freyschuss, A., Breuer, O., Diezfalusy, U., Berglund, L. and Henriksson, P. (1991) The antioxidant butylated hydroxy-toluene protects against atherosclerosis. Arteiosclerosis Thromb. 11: 15-22

Brown, M. S. and Goldstein, J. L. (1983) Lipoprotein metabolism in the macrophage: implications for cholesterol deposition in atherosclerosis. Annu. Rev. Biochem. 52: 223261

Carew, T. E., Schwenke, D. C. and Steinberg, D. (1987) Antiatherogenic effect of probucol unrelated to its hypocholesterolemic effect: evidence that antioxidants in vivo can selectively inhibit low density lipoprotein degradation in macrophage- rich fatty streaks slowing the progression of therosclerosis in the WHHL rabbit. Proc. Natl. Acad. Sci. USA. 84: 7725-7729

Carlos, T. M. and Harlan, J. M. (1990) Membrane proteins involved in phagocyte adherence to endothelium. Immunol. Rev. 114: 5-28

Chin, J. H., Azhar, S. and Hoffman B. B. (1992) Inactivation of endothelial derived relaxing factor by oxidized lipoproteins. J. Clin. Invest. 89: 10-18

Chung, H. K., Kim, S. S. and Suh, P. G. (1984) Development and evalu-ation of two site binding radioimmunoassay for human alpha fetoprotein using monoclonal antibodies. Korean J. Biochem. 16: 97-103

Fogelman, A. M., Schechter, J. S., Hokom, M., Child, J. S. and Edward, P. A., (1980) Malondialdehyde alteration of low density lipoproteins leads to cholesterol accumulation in human monocyte-macrophage. Proc. Natl. Acad. Sci. USA. 77: 2214-2218 Goldstein, J. L., Ho, Y. K., Basu, S. K. and Brown, M. S. (1979) Binding site on macrophages that mediates uptake and degradation of actetylated low density lipoprotein, producing massive cholesterol deposition. Proc. Natl. Acad. Sci. USA. 76: 333-337
Goldstein, J. L., Basu, S. K. and Brown, M. S. (1983) Receptor-mediatedendocytosis of low-density lipoproteins in cultured cells. Meth. Enzymol. 98: 241-260

Harberland, M. E., Fong, D. and Cheng, L. (1988) Malondialdehyde-altered protein occurs in atheroma of Watanabe heritable hyperlipidemic rabbits. Science. 241: 215218

Keane, W. F., Phillips, J., Kasiske, B. L., O'Donnell, M. P., Schmitz, P. G. and Kim, Y. (1990) Injurious effects of low density lipoprotein on human mesangial cells (abstract). Kidney Int. 37: 509A

Kita, T., Nagano, Y., Yokode, M., Ishii, K., Kume, N., Ooshima, A., Yoshida, H. and Kawai, C. (1987) Probocol prevents the progression of atheros-clerosis in Watanabe hereditable hyperlipidemic rabbit, an animal model for familial hypercholesterolemia. Proc. Natl. Acad. Sci. USA. 84: 5928-5931

Lee, H. S., Lee, J. S., Koh, H. I. and Ko, K. W. (1991) Intraglomerular lipid deposition in routine biopsies. Clin. Nephrol. 36: 67-75

Lee, H. S. and Koh, H. I. (1994) Visualization of binding and uptake of oxidized low density lipoproteins by cultured mesangial cells. Lab. Invest. 71: 200-208

Lehr, H. A., Becker, M., Marklund, S. L., Hübner, C., Arfors, K. E., Kohlschütter, A. and Messmer, K. (1992) Superoxide-dependent stimulation of leukocyte adhesion by oxidatively modified LDL in vivo. Arteiosclerosis Thromb. 12: 824-829

Magil, A. B., Frohlich, J. J., Innis, S. M. and Steinbrecher, V. S. (1993) Oxidized low density lipoprotein in experimental focal glomerulosclerosis. Kidney Int. 43: 1243-1250

Mueller, U. W., Hawes, C. S. and Jones, W. R. (1986) Monoclonal antibody production by hybridoma growth in Freund's adjuvant primed mice. J. Immunol. methods. 87: 193-196

Palinsky, W., M. E. Rosenfield, S. Ylä-Herttuala, G. C. Gutner, S. A. Socker, S. W. Butler, S. Parthasarathy, T. E. Carew, D. Steinberg, J. I. Witztum. (1989) Low density lipoproteins undregoes oxidative modifications in vivo. Proc. Natl. Acad. Sci. USA. 86: 1372-1376

Steinbrecher, U. P., (1987) Oxidation of human low density lipoprotein results in derivatization of lysine residues of apolipoprotein $B$ by lipid peroxide decomposition products. J. Biol. Chem. 262: 3603-3608

Suh, P. G., Chung, H. K., and Tchai, B. S. (1985) Production and charac-terization of monoclonal antibodies to estrogen. Korean J. Biochem. 17: 191-196

Ylä-Herttuala, S.,Lipton, B. A., Rosenfield, M. E., Särkioja, T.,Yoshimura, T.,Leonard E. J., Witztum, J. L. and Steinberg, D. (1991) Expression of chemoattractant protein 1 in macrophage-rich areas of human and rabbit atherosclerotic lesions. Proc. Natl. Acad. Sci. USA. 88: 5252-5256 